\title{
Tyrosyl Radical Generated by Myeloperoxidase Catalyzes the Oxidative Cross-linking of Proteins
}

\author{
Jay W. Heinecke, Wei Li, Gordon A. Francis, * and Jeffrey A. Goldstein \\ Department of Medicine, Washington University School of Medicine, St. Louis, Missouri 63110; \\ and *Department of Medicine, University of Washington, Seattle, Washington 98195
}

\begin{abstract}
Phagocytes generate $\mathrm{H}_{2} \mathrm{O}_{2}$ for use by a secreted heme enzyme, myeloperoxidase, to kill invading bacteria, viruses, and fungi. We have explored the possibility that myeloperoxidase might also convert L-tyrosine to a radical catalyst that cross-links proteins. Protein-bound tyrosyl residues exposed to myeloperoxidase, $\mathrm{H}_{2} \mathrm{O}_{2}$, and $\mathrm{L}$-tyrosine were oxidized to $0, o^{\prime}$-dityrosine, a stable product of the tyrosyl radical. The cross-linking reaction required L-tyrosine but was independent of halide and free transition metal ions; the heme poisons azide and aminotriazole were inhibitory. Activated neutrophils likewise converted polypeptide tyrosines to dityrosine. The pathway for oxidation of peptide tyrosyl residues was dependent upon L-tyrosine and was inhibited by heme poisons and catalase. Dityrosine synthesis was little affected by plasma concentrations of $\mathrm{Cl}^{-}$and amino acids, suggesting that the reaction pathway might be physiologically relevant. The requirement for free L-tyrosine and $\mathrm{H}_{2} \mathrm{O}_{2}$ for dityrosine formation and the inhibition by heme poisons support the hypothesis that myeloperoxidase catalyzes the cross-linking of proteins by a peroxidative mechanism involving tyrosyl radical. In striking contrast to the pathways generally used to study protein oxidation in vitro, the reaction does not require free metal ions. We speculate that protein dityrosine cross-linking by myeloperoxidase may play a role in bacterial killing or injuring normal tissue. The intense fluorescence and stability of biphenolic compounds may allow dityrosine to act as a marker for proteins oxidatively damaged by myeloperoxidase in phagocyte-rich inflammatory lesions. ( $J$. Clin. Invest. 1993. 91:2866-2872.) Key words: dityrosine • heme protein • neutrophil • phenoxyl radical • protein oxidation
\end{abstract}

\section{Introduction}

Partially reduced oxygen species damage cellular targets in vitro and are implicated in the pathogenesis of cancer, aging, reperfusion injury, and atherosclerosis (1). One important pathway for the generation of such reactive intermediates involves activated neutrophils and monocytes. The biochemical basis for phagocyte oxidant production is a membrane-asso-

Address correspondence to Dr. Jay W. Heinecke, Division of Lipid Research, Washington University School of Medicine, 4566 Scott Avenue, Box 8046, St. Louis, MO 63110.

Received for publication 9 November 1992 and in revised form 9 February 1993

J. Clin. Invest.

(C) The American Society for Clinical Investigation, Inc.

0021-9738/93/06/2866/07 \$2.00

Volume 91, June 1993, 2866-2872 ciated NADPH oxidase $(2,3)$, which reduces oxygen to $\mathrm{O}_{2}^{--}$ (4). The dismutation of $\mathrm{O}_{2}^{-}$yields $\mathrm{H}_{2} \mathrm{O}_{2}$ for use by a secreted heme protein, myeloperoxidase, to form $\operatorname{HOCl}(2,3,5)$. This potent oxidant is toxic to microorganisms, viruses, and tumor cells and plays a critical role in killing invading pathogens (5). In certain pathological states, normal cellular tissue may be a target for damage $(1,5)$.

We recently found that myeloperoxidase can also convert the phenolic amino acid L-tyrosine to dityrosine (6), an intensely fluorescent amino acid $(7,8)$. Studies with phenols and L-tyrosine oxidized by ferricyanide (9-11) indicate that the enzymatic reaction is likely to involve phenoxyl radical generation $(6,12)$. Radical coupling of phenoxyl radical yields orthoortho, ortho-para and para-para dimers, reflecting the distribution of free-electron density on the aromatic ring (9-11). Because the para position is blocked by a bulky substituent in tyrosyl radical, the major product of the reaction is $o, o^{\prime}-$ dityrosine $(6,9,10,12)$ :

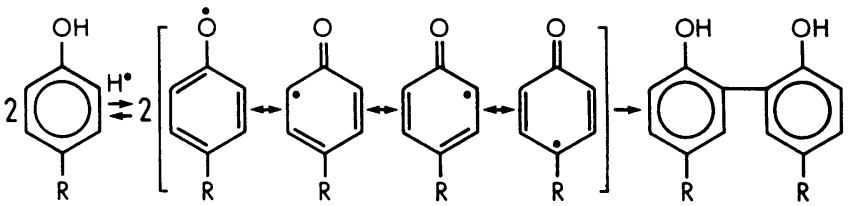

The cross-linking reaction takes place at physiological concentrations of $\mathrm{Cl}^{-}$and amino acids (6), suggesting that L-tyrosine may be an effective substrate for myeloperoxidase in vivo.

In this report, we characterize the ability of tyrosyl radical to serve as a catalyst for protein cross-linking and show that dityrosine may serve as a marker for proteins oxidatively damaged by neutrophils.

\section{Methods}

\section{Materials}

The polypeptides glutamate/tyrosine $(4: 1, \mathrm{~mol} / \mathrm{mol}$, mol wt $20,000-$ $50,000)$, lysine/tyrosine $(4: 1$, mol wt $20,000-50,000)$, glutamate/lysine/tyrosine (6:3:1, mol wt 20,000-50,000), glutamate/alanine/tyrosine (6:3:1, mol wt 20,000-50,000) and alanine/glutamate/lysine/ tyrosine (6:2:5:1, mol wt 20,000-30,000) came from Sigma Chemical Co. (St. Louis, MO). Pierce Chemical Co. (Rockford, IL) supplied $\mathrm{HCl}$ (Sequanal grade). Boehringer-Mannheim Biochemicals (Indianapolis, IN) provided BSA (fraction V; heat shock, fatty acid-free) and phenol (molecular biology grade, redistilled). Other reagents were obtained from the indicated sources $(6)$.

\section{Methods}

Dityrosine cross-linking of BSA by myeloperoxidase. Myeloperoxidase was isolated from Nonidet P-40-extracted leukocytes (13) by lectin affinity chromatography and size exclusion chromatography as described (14). The purified enzyme had an $A_{430} / A_{280}$ ratio of 0.71 (6). 
Myeloperoxidase activity was determined by guaiacol oxidation (15) and its concentration was measured spectrophotometrically $\left(E_{\mathbf{4 3 0}}\right.$ $=170 \mathrm{mM}^{-1} \mathrm{~cm}^{-1}$; reference 16 ).

Cross-linking reactions were carried out at $25^{\circ} \mathrm{C}$ in buffer A ( 50 $\mathrm{mM} \mathrm{Na} \mathrm{HPO}_{4}, 100 \mu \mathrm{M}$ diethylenetriamine pentaacetic acid, $\mathrm{pH} 7.5$ ) under conditions where protein-associated dityrosine formation was a linear function of enzyme concentration. To remove transition metal ions potentially able to catalyze tyrosine oxidation, buffer $\mathrm{A}$ was prepared with glass-distilled deionized water and passed over Chelex 100 resin (Bio-Rad Laboratories, Richmond, CA). The reaction mixture contained (final concentration) $100 \mu \mathrm{M} \mathrm{H}_{2} \mathrm{O}_{2}, 0.2 \mathrm{mM}$ L-tyrosine and $1 \mathrm{mg} / \mathrm{ml} \mathrm{BSA}$ in a final volume of $0.5 \mathrm{ml}$. After a 60 -min incubation, the reaction mixture was passed over a DEAE-Sepharose CL-6B minicolumn $\left(0.8 \mathrm{~cm}^{2} \times 1 \mathrm{~cm}\right)$ and washed with $8 \mathrm{ml}$ of buffer $A$. The protein was eluted with $2 \mathrm{ml}$ buffer B ( $6 \mathrm{M}$ guanidine hydrochloride, 50 $\mathrm{mM}$ Tris, $\mathrm{pH} \mathrm{8.0)}$. Protein-bound dityrosine production was monitored by fluorescence using excitation and emission wavelengths of 325 and $410 \mathrm{~nm}$, respectively $(7,8)$. The final concentrations of dityrosine and BSA (monitored as $A_{276}$ ) were calculated from two calibration curves for authentic dityrosine and protein in buffer $B$.

Human neutrophils. Neutrophils were prepared from human blood anticoagulated with EDTA (final concentration $5.4 \mathrm{mM}$ ) using Polymorphprep (Nycomed, Sunnyvale CA) as described (6). Cross-linking of glutamate/tyrosine $(1 \mathrm{mg} / \mathrm{ml})$ by neutrophils $\left(5 \times 10^{5}\right.$ cells in $\left.1 \mathrm{ml}\right)$ was carried out at $37^{\circ} \mathrm{C}$ in air using medium $\mathrm{A}\left(\mathrm{Ca}^{2+}\right.$ - and $\mathrm{Mg}^{2+}$-free Hank's balanced salt solution, $\mathrm{pH}$ 7.6) supplemented with $0.4 \mathrm{mM}$ L-tyrosine, $0.1 \mathrm{mM}$ diethylenetriamine pentaacetic acid, $10 \mu \mathrm{g} / \mathrm{ml}$ soybean trypsin inhibitor, $1 \mu \mathrm{g} / \mathrm{ml}$ leupeptin, $1 \mu \mathrm{g} / \mathrm{ml}$ aprotinin, and the indicated additions. The neutrophils were stimulated with $\beta$-phorbol 12-myristate 13-acetate (final concentration $200 \mathrm{nM}$ ) and maintained in suspension by intermittent inversion. At the indicated time cells were pelleted by centrifugation. The polypeptide was reisolated from the supernatant and its fluorescence determined as described for myeloperoxidase-modified BSA.

Gas chromatography/mass spectrometry of the myeloperoxidase $B S A$ and neutrophil polypeptide oxidation products. Reisolated myeloperoxidase and neutrophil-modified proteins were subjected to gas phase hydrolysis $\left(6 \mathrm{~N} \mathrm{HCl}\right.$ with $1 \%$ phenol, $\left.110^{\circ} \mathrm{C}, 40 \mathrm{~h}\right)$ in an evacuated reaction vessel that had been flushed with $\mathrm{N}_{2}$. The acid hydrolysate was loaded onto a $0.8-\mathrm{cm}^{2} \times 2.5-\mathrm{cm}$ column of Dowex- $50 \mathrm{~W}$ equilibrated with $1 \mathrm{mM} \mathrm{HCl}$. The column was extensively washed with acid and developed with $10 \mathrm{ml}$ of $2 \mathrm{M} \mathrm{NH}_{4} \mathrm{OH}$. Fluorescent fractions were pooled and concentrated by lyophilization. The preparation was adjusted to $\mathrm{pH} 8.5$ with $\mathrm{HCl}$, diluted with $\mathrm{H}_{2} \mathrm{O}$, then loaded at $1 \mathrm{ml} / \mathrm{min}$ onto a Mono Q HR5/5 column (Pharmacia, Inc., Piscataway, NJ) equilibrated with buffer $\mathrm{C}(10 \mathrm{mM}$ Hepes, $\mathrm{pH} 8.5)$ using a fast protein liquid chromatography apparatus (Pharmacia, Inc.) as described (6). After washing with buffer $\mathrm{C}(20 \mathrm{ml}), 25 \mathrm{mM} \mathrm{NaCl}$ in buffer $\mathrm{C}(50 \mathrm{ml})$, and $50 \mathrm{mM} \mathrm{NaCl}$ in buffer $\mathrm{C}(10 \mathrm{ml})$, the column was developed at 1 $\mathrm{ml} / \mathrm{min}$ with sequential linear salt gradients of $50-100 \mathrm{mM} \mathrm{NaCl}$ (20 $\mathrm{ml})$ and $100-500 \mathrm{mM} \mathrm{NaCl}(20 \mathrm{ml})$ in buffer $\mathrm{C}$.

Amino acids isolated by anion exchange chromatography were esterified by treatment with $3.5 \mathrm{~N} \mathrm{HBr}$ in $N$-propanol and acylated by the addition of ethyl acetate/heptafluorobutyric anhydride $3: 1$ ( $\mathrm{vol} / \mathrm{vol}$ ) (6). A gas chromatograph (model 5890A, Hewlett-Packard, Co., Palo Alto, CA) equipped with a mass spectrometer (model 5988A, HewlettPackard Co.) with extended mass range was used for mass spectrometry. Negative-ion chemical ionization with methane as the reagent gas and gas chromatography ( $12 \mathrm{~m} \mathrm{HP}-1$ capillary column, Hewlett-Packard Co.) were performed as described (6).

Other assays. Dityrosine was prepared as described (17). Protein was measured by the method of Lowry et al. (18) using BSA as the standard.

\section{Results}

We selected BSA for our initial studies because albumin is abundant in plasma and has been widely investigated as a tar-
Table I. Requirements of the Myeloperoxidase- $\mathrm{H}_{2} \mathrm{O}_{2}$ System for Dityrosine Cross-linking of BSA

\begin{tabular}{lc}
\hline \multicolumn{1}{c}{ Condition } & Dityrosine synthesis \\
\hline & $n m o l \cdot \mathrm{mg}^{-1}$ \\
Complete system & 1.22 \\
Complete system minus & \\
$\mathrm{H}_{2} \mathrm{O}_{2}$ & 0.07 \\
Myeloperoxidase & 0.07 \\
L-tyrosine & 0.03 \\
Complete system plus & \\
Catalase $(5 \mathrm{nM})$ & 0.07 \\
Azide (1 mM) & 0.03 \\
Aminotriazole (20 mM) & 0.13 \\
NaCl (150 mM) & 0.84 \\
Amino acids & 1.20 \\
Mannitol (10 mM) & 1.05 \\
\end{tabular}

The complete system consisted of myeloperoxidase $(13.2 \mathrm{pmol} / \mathrm{ml}$; $1.1 \mathrm{U} / \mathrm{ml}$ ), $200 \mu \mathrm{M}$ L-tyrosine, $100 \mu \mathrm{M} \mathrm{H}_{2} \mathrm{O}_{2}$, and $1 \mathrm{mg} / \mathrm{ml} \mathrm{BSA}$ in a final volume of $0.5 \mathrm{ml}$. Reactions were carried out in buffer A ( 50 $\mathrm{mM} \mathrm{Na}_{2} \mathrm{HPO}_{4}, 100 \mu \mathrm{M}$ diethylenetriamine pentaacetic acid, $\mathrm{pH}$ 7.5) at $25^{\circ} \mathrm{C}$ in air. BSA was reisolated by anion exchange chromatography after a 60-min incubation. Protein-associated fluorescence was determined as described in Methods using the excitation and emission wavelengths characteristic of dityrosine. Values are means of triplicate determinations and representative of the results found in four independent experiments. The final concentrations $(\mu \mathrm{M})$ of amino acids were: L-glutamine, 760; L-aspartate, 250; L-proline, 440; glycine, 490; L-alanine, 500; L-lysine, 260.

get for oxidative damage $(19,20)$. When BSA was incubated in chloride-free phosphate buffer ( $\mathrm{pH} 7.5$ ) with myeloperoxidase, $\mathrm{H}_{2} \mathrm{O}_{2}$ and diethylenetriamine pentaacetic acid (a potent inhibitor of metal-catalyzed reactions), the intrinsic fluorescence of BSA was little affected ( Table I). A marked increase in proteinassociated fluorescence was apparent when L-tyrosine was included in the reaction mixture. Myeloperoxidase, L-tyrosine, $\mathrm{H}_{2} \mathrm{O}_{2}$, and BSA were all required for the reaction (Table I); catalase and heme poisons were inhibitory. Protein-associated fluorescence decreased modestly when $150 \mathrm{mM} \mathrm{Cl}^{-}$was present (Table I). The reaction was little affected by mannitol (a hydroxyl radical scavenger) or amino acids at plasma concentrations (21). These results indicate that myeloperoxidase modified BSA by a peroxidative pathway that was independent of $\mathrm{Cl}^{-}$and free metal ions. The L-tyrosine requirement suggests that one product of the reaction may be dityrosine and implies that the amino acid is conveying oxidizing potential from the active site of the heme enzyme to protein tyrosyl residues.

To verify that dityrosine was responsible for the fluorescence of myeloperoxidase-modified BSA, we took advantage of the stability of the biphenolic cross-link to acid hydrolysis. BSA incubated with myeloperoxidase, L-tyrosine, and $\mathrm{H}_{2} \mathrm{O}_{2}$ was precipitated to remove free dityrosine and then hydrolyzed by exposure to $\mathrm{HCl}$ vapor. The amino acid mixture was subjected to fast protein liquid chromatography with a high resolution anion exchange column. A single major fluorescent peak eluted at the same ionic strength $(50-100 \mathrm{mM} \mathrm{NaCl})$ as dityrosine. The excitation and emission spectra of the oxidation product, as well as the $\mathrm{pH}$ dependence of fluorescence, were virtually identical to dityrosine (data not shown), strongly suggesting that the protein-associated fluorescence was due to dityrosine. 

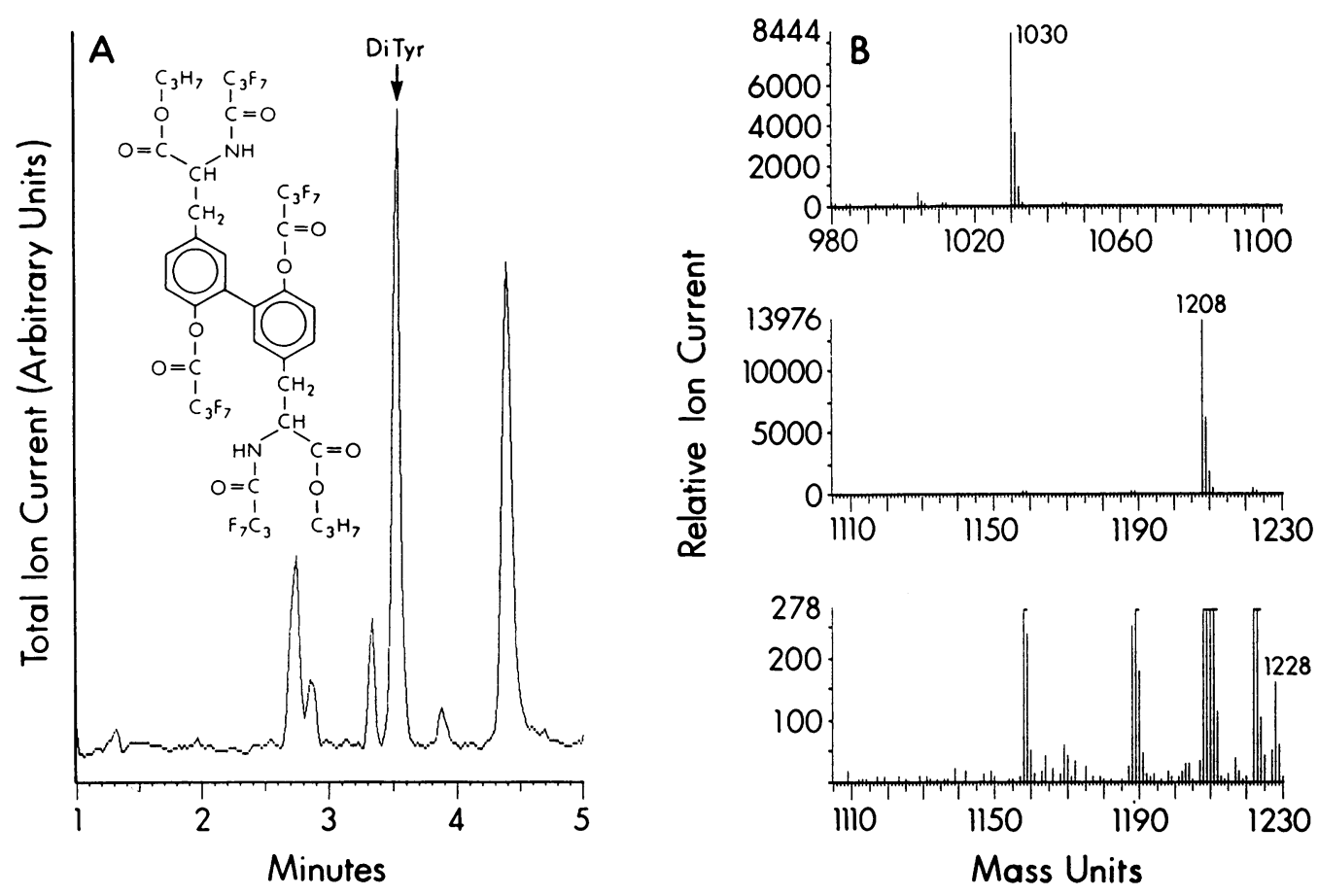

Figure 1. (A) Total ion chromatogram and $(B)$ negativeion chemical ionization mass spectrum of the $N$-propylheptafluorobutyryl derivative of the myeloperoxidase-modified BSA oxidation product. BSA modified by the complete myeloperoxidase-L-tyrosine system as described in Table I was precipitated three times with ice-cold trichloroacetic acid (final concentration 17\%) and hydrolyzed by exposure to $\mathrm{HCl}$ vapor as described in Methods. The acid hydrolysate was chromatographed on a Mono Q HR5 / 5 column, and the major peak of fluorescent amino acids was acylated and esterified as described in Methods. $(A)$ The derivative of the BSA oxidation product was analyzed by gas chromatography with negative-ion chemical ionization. Authentic dityrosine (DiTyr) exhibited the indicated retention time. Inset: The proposed structure of the dityrosine derivative. $(B)$ Mass spectrum of the major peak of the BSA oxidation product. The calculated molecular weight for the $N$-propyl-heptafluorobutyryl dityrosine derivative is 1228 . The loss of $\mathrm{HF}$ and $\mathrm{CHO}\left(\mathrm{CF}_{2}\right)_{2} \mathrm{CF}_{3}$ from a parent ion with $\mathrm{m} / \mathrm{z} 1228$ would yield ions with $\mathrm{m} / \mathrm{z} 1208$ and 1030, respectively.

To firmly establish the structure of the BSA oxidation product, we employed gas chromatography/mass spectrometry. The fluorescent amino acid (s) isolated by anion exchange chromatography was converted to its $N$-propylheptafluorobutyryl derivative. With negative-ion chemical ionization, the total ion chromatogram of the product showed a major peak whose retention time was identical to that of dityrosine (Fig. $1 A$ ). The mass spectrum of the oxidation product exhibited a small peak at $m / z 1228$ (Fig. $1 B$ ), the calculated molecular weight of the dityrosine derivative (Inset, Fig. $1 A$ ). Two major ion peaks were apparent at $m / z 1208$ and 1030 in the amino acid prepared from oxidized BSA (Fig. $1 B$ ). These peaks are characteristic of heptafluorobutyric anhydride-derivatized amino acids and correspond to loss of $\mathrm{HF}$ and $\mathrm{CHO}\left(\mathrm{CF}_{2}\right) \mathrm{CF}_{3}$, respectively, confirming that the peak observed at $\mathrm{m} / z 1228$ is the molecular ion. The mass spectrum is virtually identical to that reported for authentic dityrosine (6). The negative chemical ionization mass spectrum, in concert with the chromatographic and fluorescence spectroscopic results, conclusively identify the myeloperoxidase-modified BSA product as $o, o^{\prime}$-dityrosine.

Myeloperoxidase-modified BSA was intensely fluorescent. Based on its pH dependence (6-8), we estimate that $\sim 90 \%$ of the protein-associated fluorescence was due to dityrosine. We therefore used this property to characterize the cross-linking reaction. The myeloperoxidase- $\mathrm{H}_{2} \mathrm{O}_{2}$-L-tyrosine system rapidly oxidized BSA tyrosyl residues at physiological pH (Fig. 2 $A$ ). Protein dityrosine synthesis was optimal at 50-100 $\mu \mathrm{M}$ $\mathrm{H}_{2} \mathrm{O}_{2}$ (Fig. $2 \mathrm{~B}$ ), $200 \mu \mathrm{M}$ L-tyrosine (Fig. $2 \mathrm{C}$ ) and pH 8.0 (Fig. $2 D)$. High concentrations of L-tyrosine inhibited cross-linking, suggesting either that free dityrosine synthesis was favored or the free amino acid was quenching protein tyrosyl radical (see Discussion for a proposed mechanism).

Horseradish peroxidase is known to directly oxidize pro- tein-bound tyrosyl residues to dityrosine $(17,22)$. To determine whether myeloperoxidase is able to execute similar reactions, and to begin to explore structural features that may control protein reactivity, we studied five synthetic polypeptides ( mol wt 20,000-50,000) of limited amino acid composition and random sequence. Myeloperoxidase required free L-tyrosine to cross-link all of the polypeptides (Fig. $3 \mathrm{~A}$ ). This indicates the enzyme is likely to exhibit considerable steric hindrance in either the heme pocket or the channel for substrate access. In striking contrast, lysine/tyrosine and alanine/glutamate/lysine/tyrosine were cross-linked by horseradish peroxidase in the absence of L-tyrosine (Fig. $3 \mathrm{~B}$ ), showing the enzyme is able to directly interact with polypeptide tyrosyl residues. This may reflect electron transfer at an exposed heme edge since reducing agents are unable to interact with the iron of horseradish peroxidase (23). Facile cross-linking of lysine/ tyrosine suggests the active site of the enzyme is embedded in a negatively charged domain that attracts basic proteins. Consonant with this hypothesis, the acidic polypeptide glutamate/ tyrosine was not a substrate for cross-linking in the absence of L-tyrosine. These results imply that electrostatic effects may be one important factor controlling cross-linking by horseradish peroxidase.

We used the glutamate/tyrosine polypeptide, an excellent substrate for cross-linking by the myeloperoxidase- $\mathrm{H}_{2} \mathrm{O}_{2}$-L-tyrosine system (Fig. $3 \mathrm{~A}$ ), to investigate the potential role of neutrophils in dityrosine synthesis. Cells activated with phorbol ester rapidly cross-linked the synthetic polypeptide (Fig. 4 $A$ ). As with the myeloperoxidase $-\mathrm{H}_{2} \mathrm{O}_{2}$ system, the reaction required L-tyrosine (Table II): it was inhibited by catalase, an $\mathrm{H}_{2} \mathrm{O}_{2}$ scavenger ( Fig. $4 A$ ), and by the heme poisons aminotriazole and azide (Table II). Neither mannitol nor amino acids were inhibitory (Table II). The optimum L-tyrosine concen- 

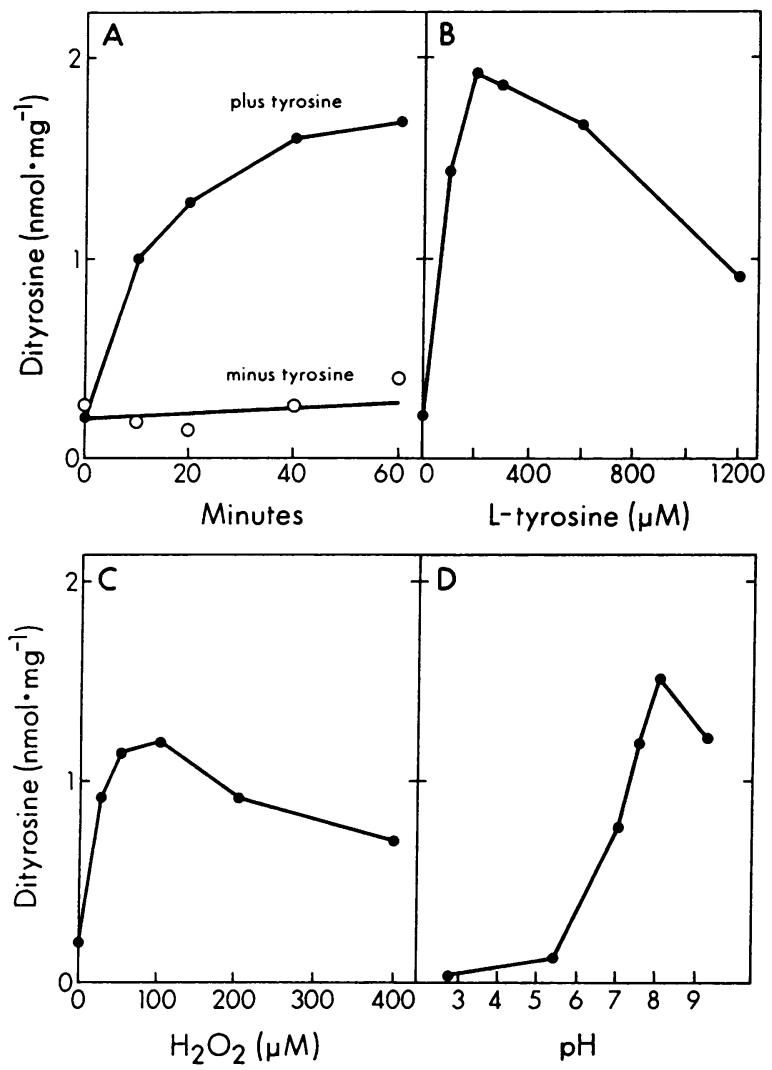

Figure 2. Dityrosine cross-linking of BSA by the myeloperoxidase$\mathrm{H}_{2} \mathrm{O}_{2}$-L-tyrosine system. Reactions were initiated by the addition of myeloperoxidase $(6.6 \mathrm{pmol}$ ) to $0.5 \mathrm{ml}$ of buffer $\mathrm{A}$ ( $\mathrm{pH} 7.5$ ) supplemented with $0.2 \mathrm{mM}$ L-tyrosine, $100 \mu \mathrm{M} \mathrm{H}_{2} \mathrm{O}_{2}$, and $1 \mathrm{mg} / \mathrm{ml} \mathrm{BSA}$. Dityrosine cross-linking of BSA was measured by protein-associated fluorescence after a 60 -min incubation at $25^{\circ} \mathrm{C}$ in air as described in Methods. Conditions were varied by assaying the reaction mixture at the indicated times $(A)$ or with the indicated final concentration of L-tyrosine $(B), \mathrm{H}_{2} \mathrm{O}_{2}(C)$, and hydrogen ion $(D)$. Values are means of duplicate determinations and representative of the results found in three independent experiments.

tration was $0.4-0.8 \mathrm{mM}$ (Fig. $4 \mathrm{~B}$ ). The L-tyrosine requirements for crosslinking of BSA by myeloperoxidase (Fig. $1 B$ ) and of polypeptide by neutrophils (Fig. $4 \mathrm{~B}$ ) were distinct, perhaps reflecting differences in the substrates or the incubation conditions ( such as the $\mathrm{Cl}^{-}$present in the neutrophil medium). Superoxide dismutase stimulated dityrosine cross-linking fivefold (Fig. $4 \mathrm{~A}$ ). This may be due to either an increase in $\mathrm{H}_{2} \mathrm{O}_{2}$ yield or accelerated disappearance of $\mathrm{O}_{2}^{--}$, which is known to repair tyrosyl radical (24).

The fluorescent neutrophil glutamate/tyrosine oxidation product was shown to be dityrosine by gas chromatography/ mass spectrometry. To ensure removal of free dityrosine, modified polypeptide was dialyzed, reisolated by anion exchange chromatography, and then subjected to precipitation. The polypeptide was acid-hydrolyzed and the fluorescent product was isolated by high-resolution anion exchange chromatography (Fig. $5 \mathrm{~A}$ ). A major peak of fluorescence eluted at the same ionic strength as authentic dityrosine. The isolated fluorescent amino acid(s) was esterified, acylated, and then subjected to negative-ion chemical ionization mass spectrometry (Fig. 5 $B)$. The mass spectra of the derivatized neutrophil oxidation

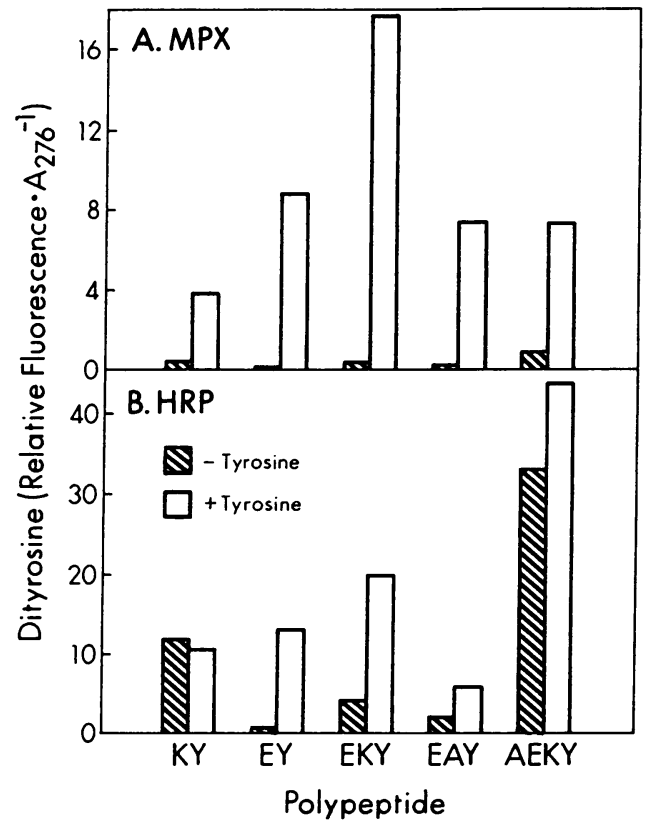

Figure 3. Oxidation of polypeptide tyrosyl residues by $(A)$ myeloperoxidase and $(B)$ horseradish peroxidase. Reactions were carried out in buffer $\mathrm{A}$ supplemented with $0.2 \mathrm{mM}$ L-tyrosine (open bars), 100 $\mu \mathrm{M} \mathrm{H}_{2} \mathrm{O}_{2}, 1 \mathrm{mg} / \mathrm{ml}$ polypeptide, and either $20 \mathrm{nM}$ myeloperoxidase or $75 \mathrm{nM}$ horseradish peroxidase for $120 \mathrm{~min}$ at $25^{\circ} \mathrm{C}$ in air. L-tyrosine was omitted from the reaction mixture where indicated (striped bars). The composition of the random sequence polypeptides were: lysine/tyrosine, $(K Y, 4: 1, \mathrm{~mol} / \mathrm{mol})$; glutamate/tyrosine $(E Y, 4: 1)$; glutamate/lysine/tyrosine ( $E K Y, 6: 3: 1)$; glutamate/alanine/tyrosine $(E A Y, 1: 1: 1)$; and alanine/glutamate/lysine/tyrosine ( $A E K Y$,

6:2:5:1). To remove free dityrosine, proteins were precipitated with trichloroacetic acid (final concentration $20 \%$ ) at $4^{\circ} \mathrm{C}$, pelleted by centrifugation, solubilized in $\mathrm{H}_{2} \mathrm{O}$ with sonication, and acid-precipitated a second time. After washing with ice-cold ether, the pellet was resolubilized by heating and sonication in $6 \mathrm{M}$ guanidine hydrochloride, $50 \mathrm{mM}$ Tris ( $\mathrm{pH} \mathrm{8.0)}$. Dityrosine was determined by fluorescence as described in Methods. Protein values were determined by $A_{276}$ and are corrected for aggregation (with consequent light scattering) by subtracting the increase in $A_{314}$.

product (Fig. $5 B$ ), the myeloperoxidase BSA oxidation product (Fig. $1 B$ ) and dityrosine were virtually identical (6), with small molecular ion peaks at $m / z 1228$ and major ion peaks at $m / z 1208$ and 1030 .

\section{Discussion}

Our results, taken together, indicate that the myeloperoxidase$\mathrm{H}_{2} \mathrm{O}_{2}$ system of activated neutrophils can form dityrosine cross-links in proteins at physiological concentrations of chloride and amino acids. In contrast to the mechanisms generally used to study protein oxidation in vitro $(1,20)$, the reaction is independent of free transition metal ions. The requirement for L-tyrosine suggests that tyrosyl radical serves as a diffusible catalyst for the reaction $(9-11)$. The following pathway is consonant with these data and peroxidase chemistry (25):

myeloperoxidase $+\mathrm{H}_{2} \mathrm{O}_{2} \rightarrow$ compound $\mathrm{I}+\mathrm{H}_{2} \mathrm{O}$

compound I + L-tyrosine $\rightarrow$ compound II + tyrosyl $1^{\bullet}$ 

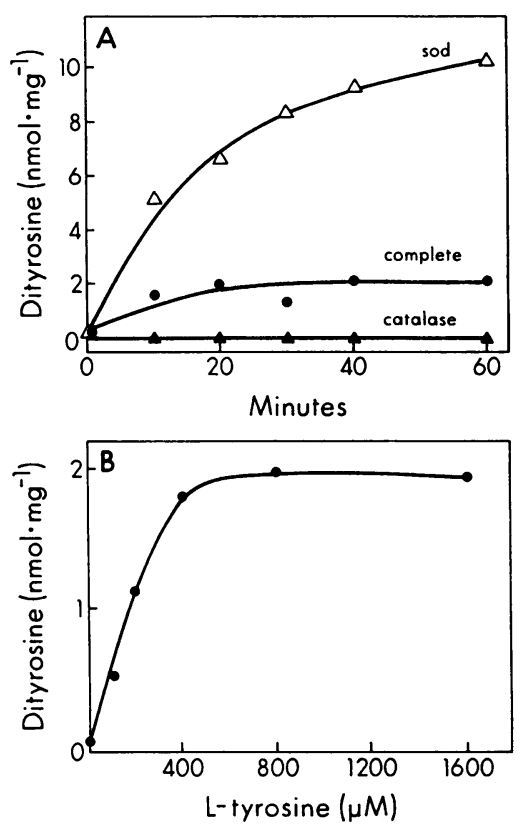

Figure 4. $(A)$ Progress curve and $(B)$ L-tyrosine concentration dependence of dityrosine formation in polypeptide glutamate/tyrosine $(4: 1, \mathrm{~mol} / \mathrm{mol})$ by activated human neutrophils. $5 \times 10^{5}$ neutrophils were incubated at $37^{\circ} \mathrm{C}$ in $1 \mathrm{ml}$ medium A supplemented with $0.4 \mathrm{mM}$ L-tyrosine and $1 \mathrm{mg} / \mathrm{ml}$ polypeptide (complete). Where indicated, superoxide dismutase (sod; $5 \mu \mathrm{g} / \mathrm{ml}$ ) or catalase $(5 \mu \mathrm{g} / \mathrm{ml})$ was included in the medium. ( $A$ ) After stimulation of the cells with $200 \mathrm{nM}$ phorbol myristate acetate, the medium was removed at the indicated time and clarified by centrifugation. The polypeptide was reisolated from the supernatant and its fluorescence determined as described in Methods. ( $B$ ) After a 60-min incubation at the indicated final concentration of L-tyrosine, protein-associated dityrosine was measured as described in Methods. Values are corrected for the fluorescence observed in the absence of polymer and are means of duplicate determinations. Similar results were found in three independent experiments.

compound II $+\mathrm{RH} \rightarrow$ myeloperoxidase $+\mathrm{H}_{2} \mathrm{O}+\mathrm{R}$

tyrosyl $^{\bullet}+$ protein-tyrosine $\rightleftarrows$

$$
\text { L-tyrosine + protein-tyrosyl }{ }^{\bullet}
$$

Sum: $\mathrm{H}_{2} \mathrm{O}_{2}+$ protein-tyrosine $+\mathrm{RH} \rightarrow$

$$
2 \mathrm{H}_{2} \mathrm{O}+\text { protein-tyrosyl }{ }^{\bullet}+\mathrm{R}
$$

Our interpretation is that myeloperoxidase compound I, a ferryl $-\pi$ cation protein radical (25), converts L-tyrosine to tyrosyl radical. Tyrosyl radical diffuses from the active site of the enzyme: when this selectively reactive intermediate productively encounters a protein tyrosyl residue, it abstracts an electron, forming a protein tyrosyl radical and regenerating L-tyrosine. The net result is the peroxidation of protein tyrosyl residues to tyrosyl radical.

The redox midpoint potentials for oxidation of $\mathrm{Cl}^{-}$to $\mathrm{HOCl}$ and tyrosine to phenoxyl radical are $1.07 \mathrm{~V} \mathrm{(25)}$ and $0.94 \mathrm{~V}(26)$, respectively. Myeloperoxidase compound I, the intermediate that converts $\mathrm{Cl}^{-}$to $\mathrm{HOCl}(5,25)$, is thus thermodynamically competent to form tyrosyl radical. The capability of myeloperoxidase compound II, a less oxidizing intermediate (25), to generate tyrosyl radical is unknown. It also remains to be determined if other amino acids are oxidized by myeloperoxidase. Because L-tyrosine is the most easily oxidized aromatic amino acid (26), and phenols are known to be unusually susceptible to one electron transfer reactions (8-10), L-tyro-
Table II. Requirements for Dityrosine Cross-linking of Polypeptide Glutamate/Tyrosine by Human Neutrophils

\begin{tabular}{lc}
\hline & Dityrosine synthesis \\
\hline & $n m o l \cdot m g^{-1}$ \\
Complete system & 1.81 \\
Complete system minus & \\
Cells & 0.12 \\
Phorbol myristate acetate & 0.11 \\
L-tyrosine & 0.12 \\
Complete system plus & \\
Azide (1 mM) & 0.27 \\
Aminotriazole (20 mM) & 0.23 \\
Catalase (5 nM) & 0.23 \\
Amino acids & 1.77 \\
Mannitol (10 mM) & 1.50 \\
\end{tabular}

The complete system consisted of $5 \times 10^{5}$ neutrophils in $1 \mathrm{ml}$ of medium A ( $\mathrm{pH} 7.6 ; 147 \mathrm{mM} \mathrm{Cl}^{-}$) containing $0.4 \mathrm{mM} \mathrm{L-tyrosine} \mathrm{and} 1$ $\mathrm{mg} / \mathrm{ml}$ polypeptide glutamate/tyrosine $(4: 1, \mathrm{~mol} / \mathrm{mol})$. Cells were stimulated with $200 \mathrm{nM}$ phorbol myristate acetate and incubated at $37^{\circ} \mathrm{C}$ in air. After a 60 -min incubation, polypeptide was isolated from the medium by anion exchange chromatography and proteinassociated fluorescence determined as described in Methods. Values are means of triplicate determinations and representative of the results found in three independent experiments.

* Cells received the solvent (dimethyl sulfoxide) used for phorbol ester. ‡ Concentrations given in Table I.

sine may be the preferred amino acid substrate for enzymatic peroxidation.

The proposed intermediate in the reaction pathway-protein tyrosyl radical-may have several fates. First, it could cross-link with a free tyrosyl radical, yielding tyrosylated protein. Second, it might interact with a second suitably juxtaposed protein tyrosyl radical, forming intra- and intermolecular cross-links. Finally, protein tyrosyl radical could be repaired by an electron donor such as $\mathrm{O}_{2}^{--}(24)$, L-tyrosine (9-11), vitamin E (24), and ascorbate (24). The repair reaction may explain both the stimulation of neutrophil-dependent dityrosine cross-linking by superoxide dismutase and the inhibition of myeloperoxidase-catalyzed BSA cross-linking by high concentrations of L-tyrosine.

In contrast to hydroxyl radical, $\left(\mathrm{HO}^{\circ}\right)$, the tyrosyl radical is relatively stable and selectively reactive $(9,10,27,28)$. Dityrosine may be a significant product of tyrosyl radical in biological systems, making the compound a potentially useful marker for oxidation. An important question is the specificity of myeloperoxidase for dityrosine formation. Other peroxidases, including horseradish peroxidase and lactoperoxidase, catalyze dityrosine synthesis $(12,29)$. Both ultraviolet irradiation $(8$, $28)$ and $\mathrm{HO}^{\circ}(9,10,19)$ can oxidize L-tyrosine to dityrosine. Although sunlight is thought to promote dityrosine formation in human cataracts (30), it is unlikely to effect reactions in the bloodstream. A physiological role for $\mathrm{HO}^{\circ}$ is also uncertain. Plasma apparently lacks the free metal ions necessary for $\mathrm{HO}^{\circ}$ generation in vitro and contains high concentrations of metabolites that rapidly react with this radical. Thus, under the condi- 

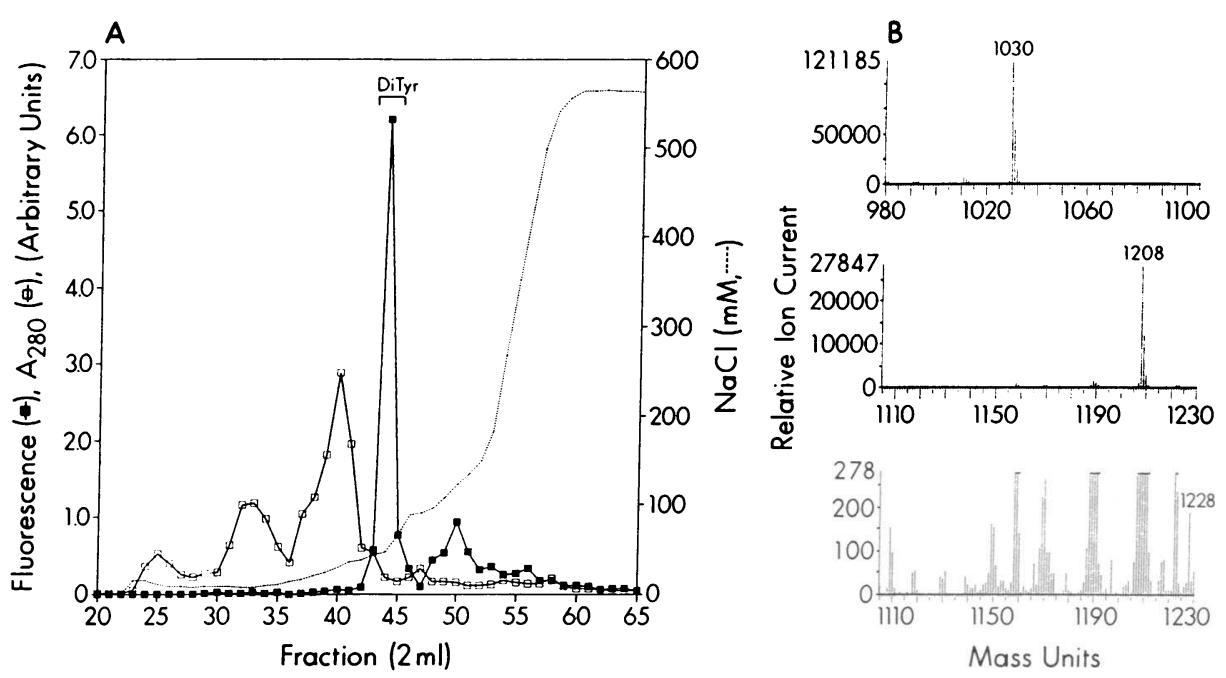

Figure 5. (A) Anion exchange chromatography of amino acid hydrolysate and $(B)$ negative-ion chemical ionization mass spectrum of the $N$-propyl-heptafluorobutyryl derivative of neutrophil polypeptide oxidation product. Glutamate/tyrosine $(4: 1, \mathrm{~mol} / \mathrm{mol})$ was modified by the complete neutrophil-L-tyrosine system as described in Table II. To remove free dityrosine from the medium, the polypeptide was dialyzed versus $\mathrm{H}_{2} \mathrm{O}$, reisolated by anion exchange chromatography, and precipitated twice with ice-cold trichloroacetic acid (final concentration $17 \%$ ). Neutrophil-modified polypeptide was then hydrolyzed by exposure to $\mathrm{HCl}$ vapor, and the amino acids were subjected to fast protein liquid chromatography at $1 \mathrm{ml} /$

min on a Mono Q HR5 / 5 column while collecting 2-ml fractions as described in Methods. Dityrosine (DiTyr) elutes from the column at the indicated ionic strength. $(B)$ The major peak of fluorescent amino acids was derivatized and subjected to gas chromatography/mass spectrometry as described in Methods. The proposed structure of the dityrosine derivative is presented in Fig. $1 \mathrm{~A}$ (inset).

tions that generally exist in vivo, dityrosine is likely to be a distinctive product of a peroxidase- $\mathrm{H}_{2} \mathrm{O}_{2}$ system.

Dityrosine synthesis may be widespread in nature. Both the nascent sea urchin embryo (31) and the yeast spore (32) employ heme proteins to cross-link their protective protein coats; dityrosine is also abundant in insect ligaments (7). Different mechanisms than the one we have proposed for the myeloperoxidase- $\mathrm{H}_{2} \mathrm{O}_{2}$-L-tyrosine system may be involved, however. In the sea urchin embryo, ovoperoxidase directly oxidizes protein-bound tyrosyl residues at fertilization (31).

A marker for proteins modified by myeloperoxidase would be a powerful tool for studying the importance of neutrophil and monocyte activation in the pathogenesis of disease states ranging from atherogenesis to cancer. Such reactions may take place in protected extracellular microenvironments, where phagocytes are abundant and local antioxidants that scavenge tyrosyl radical might be depleted. Dityrosine should be readily detectable in tissue because biphenolic compounds are intensely fluorescent $(7,8)$ and stable to acid hydrolysis $(7,8$, 17). Myeloperoxidase cross-links proteins at physiological concentrations of $\mathrm{Cl}^{-}$and L-tyrosine, raising the possibility that tyrosyl radical plays a role in the phagocyte inflammatory response. If similar cross-linking reactions take place during injury to tissue or bacterial killing, dityrosine may serve to mark protein targets oxidatively damaged by phagocytes.

\section{Acknowledgments}

We thank Drs. D. D. Hickstein and S. J. Klebanoff for providing detergent-extracted leukocytes, W. R. Sherman for advice on mass spectrometry, and L. Sage, W. Parsons, and C. F. Semenkovich for critical reading of the manuscript. Gas chromatography/mass spectrometry experiments were performed at the Washington University School of Medicine Mass Spectrometry Facility (supported by National Institutes of Health grants RR00954 and AM20579).

This research was supported by a Grant-in-Aid from the American Heart Association, the Medical Research Council of Canada, the Alberta Heritage Foundation for Medical Research, and award R01 HD29920 from the National Institutes of Health.

\section{References}

1. Stadtman, E. R. 1992. Protein oxidation and aging. Science (Wash. DC). 257:1220-1224.

2. Segal, A. W. 1989. The electron transport chain of the microbicidal oxidase of phagocytic cells and its involvement in the molecular pathology of chronic granulomatous disease. J. Clin. Invest. 83:1785-1793.

3. Babior, B. M. 1987. The respiratory burst oxidase. Trends Biochem. Sci. 12:241-243.

4. Babior, B. M., R. S. Kipnes, and J. T. Curnutte. 1973. Biological defense mechanism: The production by leukocytes of superoxide, a potential bactericidal agent. J. Clin. Invest. 52:741-744.

5. Klebanoff, S. J., and R. A. Clark. 1978. The Neutrophil: Function and Clinical Disorders. North Holland Publishing Co., Amsterdam.

6. Heinecke, J. W., W. Li, H. L. Daenke III, and J. A. Goldstein. 1993 Dityrosine, a specific marker of oxidation, is synthesized by the myeloperoxidasehydrogen peroxide system of human neutrophils and macrophages. J. Biol. Chem. 268:4069-4077.

7. Anderson, S. O. 1966. Covalent cross-links in a structural protein, resilin Acta Physiol. Scand. 66(Suppl. 263):1-81.

8. Lehrer, S. S., and G. D. Fasman. 1967. Ultraviolet irradiation effects in poly-L-tyrosine and model compounds: identification of bityrosine as a photoproduct. Biochemistry. 6:757-767.

9. Musso, H. 1963. Phenol oxidation reactions. Angew. Chem. Int. Ed. Engl. 2:723-735.

10. Scott, A. I. 1965. Oxidative coupling of phenolic compounds. $Q$. Rev. Chem. Soc. (Lond.). 19:1-35.

11. Sealy, R. C., L. Harman, P. R. West, and R. P. Mason. 1985. The electron spin resonance spectrum of the tyrosyl radical. J. Am. Chem. Soc. 107:34013406.

12. Gross, A. J., and I. W. Sizer. 1959. The oxidation of tyramine, tyrosine and related compounds by peroxidase. J. Biol. Chem. 234:1611-1614.

13. Hickstein, D. D., J. Ozols, S. A. Williams, J. O. U. Baenager, R. M. Locksley, and G. J. Roth. 1987. Isolation and characterization of the receptor on human neutrophils that mediates cellular adhesion. J. Biol. Chem. 262:55765580 .

14. Rakita, R. M., B. R. Michel, and H. Rosen. 1990. Differential inactivation of Escherichia coli membrane dehydrogenases by a myeloperoxidase-mediated antimicrobial system. Biochemistry. 29:1075-1080.

15. Klebanoff, S. J., Waltersdorph, and H. Rosen. 1984. Antimicrobial activity of myeloperoxidase. Methods Enzymol. 105:399-403.

16. Morita, Y., H. Iwamoto, S. Aibara, T. Kobayashi, and E. Hasegawa. 1986. Crystallization and properties of myeloperoxidase from normal human leukocytes. J. Biochem. 99:761-770.

17. Amado, R., R. Aeschbash, and H. Neukon. 1984. Dityrosine: in vitro production and characterization. Methods Enzymol. 107:377-388.

18. Lowry, O. H., N. J. Rosenbrough, A. L. Farr, and R. J. Randall. 1951. Protein measurement with the folin phenol reagent. J. Biol. Chem. 193:265-275. 
19. Davies, K. J. 1987. Protein damage and degradation by oxygen radicals. $J$. Biol. Chem. 262:9895-9901.

20. Meucci, E., Mordente, and G. E. Martorana. 1991. Metal-catalyzed oxidation of human serum albumin: conformational and functional changes. J. Biol. Chem. 266:4692-4699.

21. Ibbott, F. A. 1974. Amino acids and their metabolites. In Clinical Chemistry. R. J. Henry, D. C. Cannon, and J. W. Winkelman, editors. Harper \& Row, Publishers, Inc., Hagerstown, MD. 565-638.

22. Aeschbach, R., R. Amado, and H. Neukom. 1976. Formation of dityrosine crosslinks in proteins by oxidation of tyrosine residues. Biochim. Biophys. Acta. 439:292-301.

23. Ator, M. A., S. K. David, and P. R. Ortiz de Montellano. 1987. Structure and catalytic mechanism of horseradish peroxidase. J. Biol. Chem. 262:1495414960.

24. Hunter, E. P. L., M. F. Desrosiers and M. G. Simic. 1989. The effect of oxygen, antioxidants, and superoxide radical on tyrosine phenoxyl radical dimerization. Free Radical Biol. Med. 6:581-585.
25. Hurst, J. K., and W. C. Barette, Jr. 1989. Leukocytic oxygen activation and microbicidal oxidative toxins. Crit. Rev. Biochem. Mol. Biol. 24:271-328.

26. DeFelippis, M. R., C. P. Murthy, M. Faraggi, and M. H. Klapper. 1989. Pulse radiolytic measurement of redox potentials: the tyrosine and tryptophan radicals. Biochemistry. 28:4847-4853.

27. Prince, R. C. 1988. Tyrosine radicals. Trends Biochem. Sci. 13:286-288.

28. Malencik, D. A., and S. R. Anderson. 1987. Dityrosine formation in calmodulin. Biochemistry. 25:695-704.

29. Bayse, G. S., A. W. Michaels, and M. Morrison. 1972. The peroxidasecatalyzed oxidation of tyrosine. Biochim. Biophys. Acta. 284:34-42.

30. Garcia-Castineiras, S., J. Dillon, and A. Spector. 1978. Detection of bityrosine in cataractous human lens protein. Science (Wash. DC). 199:897-899.

31. Foerder, C. A., and B. M. Schapiro. 1977. Release of ovoperoxidase from sea urchin eggs hardens the fertilization membrane with tyrosine crosslinks. Proc. Natl. Acad. Sci. USA. 74:4214-4218.

32. Briza, P., G. Winkler, H. Kalchhauser, and M. Breitenbach. 1986. Dityrosine is a prominent component of the yeast ascospore wall. J. Biol. Chem. 261:4288-4294. 